\title{
Introduction: combat damage-control resuscitation/surgery and beyond
}

\section{"The most sophisticated intensive care becomes unnecessarily expensive terminal care once the pre-ICU system fails"} - Dr. Peter Safar. ${ }^{1}$

even years have passed since Canada ended its combat mission in Afghanistan and the Canadian fournal of Surgery published the first Canadian Forces supplement on war surgery. ${ }^{2}$ In the last decade, meticulous international data collection and research efforts have led to significant improvements in military trauma care. In optimal conditions, experienced health care providers can be challenged by trauma casualty care. Combat missions further complicate the challenge; the austere environment and scarcity of resources hinder optimal care to the wounded. Timely treatment is one of the most important variables that can affect trauma patients' outcomes. Remote locations and tactical limitations may prolong evacuation times - a situation similar to trauma that occurs in remote locations in Canada under extreme weather conditions.

Historically, medical care in the battlefield has been a milieu for providers to learn and promote further trauma research in both military and civilian medical institutions. During both Iraq and Afghanistan conflicts, the establishment of clear injury definitions with quantifiable outcomes through detailed data collection and well-supported, focused research improved outcomes. ${ }^{3,4}$ Among the most significant improvements in tactical combat casualty care (TCCC) in recent years is the wide implementation of tourniquets, which decreased mortality from extremity hemorrhage by $85 \% .{ }^{4}$ Hemostatic dressings with gauze impregnated with organic agents, such as chitosan or nonwoven kaolin, were found to be superior to regular gauze in controlling compressible hemorrhage. ${ }^{5}$ A significant cause of combat deaths is from noncompressible torso hemorrhage. Resuscitative endovascular balloon occlusion of the aorta (REBOA) has been used successfully in hospital settings to resuscitate those patients. In this supplement, Smith and McAlister ${ }^{6}$ present proof of concept for a novel REBOA system that may be used in the prehospital setting.

Early administration of tranexamic acid (TXA), which was shown in the CRASH-2 trial to reduce mortality, ${ }^{7}$ has been applied in combat situations. Balanced blood component transfusion, with a 1:1:1 ratio between red blood cells, plasma and platelets, became the gold standard for treatment of hemorrhagic trauma, ${ }^{8}$ but it is difficult to implement in austere or prehospital settings. Fresh whole blood donated by uninjured soldiers to a casualty in shock may be an effective strategy in austere circumstances to correct the various derangements caused by hemorrhage. Both TXA and fresh whole blood were used during the recent deployment in Iraq. ${ }^{9}$

Early surgery remains the key to providing medical care to trauma patients. The composition of forward surgical teams vary according to their designated mission from a team of approximately 20, including 4 surgeons, 8 nurses and 2 surgical technicians, to a 4-person jump team that consists of 1 to 2 surgeons, 1 nurse and 1 surgical technician. ${ }^{10}$ Leasiolagi and colleagues ${ }^{11}$ use their experience of a small team in a far-forward position that improvised a mobile operating room to define the specifications of an ideal unit.

The measures described above as well as improved personal protective equipment have resulted in better survivability, but combat wounds involving the extremities continue to be a problem. Smith and colleagues ${ }^{12}$ describe the greater injury severity present if an upper-extremity amputation is part of the polytrauma from improvised explosive devices as well as its consequences for rehabilitation. The Canadian Armed Forces physical rehabilitation program, built upon a civilian-military partnership, is described by Besemann and colleagues. ${ }^{13}$ The multidisciplinary team approach focuses on physical, psychosocial and spiritual aspects of a person's well-being by empowering patients to foster self-efficacy, find meaning in life events and set high-level life goals. This holistic approach may be particularly necessary when suicide bombing is the mechanism of injury. A protocol for immediate actions by trauma teams to care for victims of suicide bombing is proposed in this supplement. ${ }^{14}$

Military trauma care has undergone a significant leap in recent years. Those new developments have impacted how NATO countries develop their core and enhanced field medical treatment facilities. More importantly, as described by DaCambra and colleagues, ${ }^{9}$ those experiences showed the importance of multinational interoperability and cooperation in effecting cohesive medical care in present and future coalition surgical facilities. ${ }^{9}$

Multinational interoperability derives from a unique relationship between higher medical command collaboration, international training and adherence to common standards for equipment and clinical practice. Furthermore, utilization of telemedicine technology to provide video calling for virtual consults has the potential to 
improve medical care where medical specialities are unavailable in an austere deployed setting. For example, Donham and Wickett ${ }^{15}$ discuss the case of a critically ill military working dog for whom veterinary services were limited and nonveterinary providers, through the use of FaceTime interactive video calling, consulted the dog's veterinarian in the United States to assist in the evaluation, treatment and prioritization of medical evacuation.

Finally, the translation of research from the laboratory to the clinic has become a benchmark of success in medicine. The complexity of human physiology and its interaction with the environment warrant the development of safe and effective therapies. Kao and colleagues ${ }^{16}$ put forth a simple inhaled indomethacin to prevent worsening lung inflammation to acute respiratory distress syndrome in a blunt chest trauma rat model, which eventually can be evolved into practical application to human blunt chest trauma. It is through mutual learning in the battlefield, the laboratory and the civilian trauma environment that we continue to improve care to the injured and, ultimately save lives.

\section{Capt (Navy) Raymond L. Kao, MD}

Affiliation: From the Royal Canadian Medical Service; and the Department of Medicine, Schulich School of Medicine and Dentistry,Western University, London, Ont.

\section{Competing interests: None declared.}

Disclaimer: The views expressed in this paper are those of the authors and do not constitute the views or policies of the Canadian Armed Forces.

DOI: $10.1503 /$ cjs. 014418

\section{References}

1. Safar P. Critical care medicine: Quo vadis? Crit Care Med 1974;2:1-5.

2. Tien HC. Introduction to the Canadian Forces operational medicine supplement. 7 Trauma 2011;71:S396.
3. Eastridge BJ, Mabry RL, Seguin P, et al. Death on the battlefield (2001-2011): implications for the future of combat casualty care. $\mathcal{F}$ Trauma Acute Care Surg 2012;73(Suppl 5):S431-7.

4. Lipsky AM, Ganor O, Abramovich A, et al. Walking between the drops: Israeli defense forces' fluid resuscitation protocol. 7 Emerg Med 2013;44:790-5.

5. Holcomb J, Macphee M, Hetz S, et al. Efficacy of a dry fibrin sealant dressing for hemorrhage control after ballistic injury. Arch Surg 1998;133:32-5.

6. Smith SA, McAlister VC. A novel REBOA system: prototype and proof of concept. Can 7 Surg 2018;61:S188-94.

7. Roberts I, Shakur H, Coats T, et al. The CRASH-2 trial: a randomised controlled trial and economic evaluation of the effects of tranexamic acid on death, vascular occlusive events and transfusion requirement in bleeding trauma patients. Health Technol Assess 2013;17:1-79.

8. Holcomb JB, Tilley BC, Baraniuk S, et al. Transfusion of plasma, platelets, and red blood cells in a 1:1:1 vs a 1:1:2 ratio and mortality in patients with severe trauma: the PROPPR randomized clinical trial. FAMA 2015;313:471-82.

9. DaCambra MP, Kao RL, Berger C, et al. Utilization profile of the Canadian-led coalition Role 2 Medical Treatment Facility in Iraq: the growing requirement for multinational interoperability. Can $\mathcal{F}$ Surg 2018;61:S195-202.

10. Counihan TC, Danielson PD. The 912th forward surgical team in Operation New Dawn: employment of the forward surgical team during troop withdrawal under combat conditions. Mil Med 2012;177:1267-71.

11. Leasiolagi J, Holton T, Doyle K, et al. Proposed specifications of a mobile operating room for far-forward surgery. Can 7 Surg 2018;61: S180-3.

12. Smith SA, DaCambra MP, McAlister VC. Impact of traumatic upperextremity amputation on the outcome of injury caused by an antipersonnel improvised explosive device. Can 7 Surg 2018;61:S203-7.

13. Besemann M, Hebert J, Thompson JM, et al. Reflections on recovery, rehabilitation and reintegration of injured service members and veterans from a bio-psychosocial-spiritual perspective. Can 7 Surg 2018;61:S219-31.

14. Kao RL, McAlister VC. Care of victims of suicide bombing. Can 7 Surg 2018;61:S184-7.

15. Donham B, Wickett ML. Novel use of FaceTime video calling in a deployed setting to assist with the care of a military working dog. Can 7 Surg 2018;61:S232-4.

16. Kao RL, Huang W, Martin CM, et al. The effect of aerosolized indomethacin on lung inflammation and injury in a rat model of blunt chest trauma. Can F Surg 2018;61:S208-17. 